\title{
A Survey of Self-perceived Physical Discomforts and Health Behaviors Related to Personal Protective Equipment of Indian Dental Professionals during COVID-19 Pandemic
}

\author{
Kalpana Bansal ${ }^{1}$, Seba Saji ${ }^{2}$, Vijay P Mathur ${ }^{3}$, Morankar Rahul $^{4}$, Nitesh Tewari ${ }^{5}$
}

\begin{abstract}
Aim: In the current situation of COVID-19 pandemic, personal protective equipment has to be mandatorily worn by dental professionals all times in the dental clinical settings. The aim of this study was to assess the physical discomforts and related health issues faced by dental professionals while wearing personal protective equipment in dental clinical settings during the pandemic.

Methods: This was an online cross-sectional survey conducted in November to December 2020 among dental professionals of various regions of country. A prevalidated questionnaire was sent through email/WhatsApp groups to 650 dental professionals. Informed consent was taken from all the participants. Information was collected about the demographics, type of dental set-up, average daily working hours, types of PPE worn, physical discomforts related to the various procedures in dentistry. Association was analyzed between demographics and the discomforts using Chi-square test.

Results: A total of 309 dental professionals (163 females, 146 males) from all parts of the country responded to the online questionnaire. Maximum respondents were postgraduates or pursuing MDS (79\%), majority (42.1\%) were pediatric dentists followed by general dentists. Sweating, difficulty in vision, difficulty in breathing, and headache were the common discomforts reported by majority of the respondents. Headache and difficult breathing were more significantly associated with female dental professionals $(p<0.05)$. N95 wear was associated with breathing difficulty (56\%) while use of faceshield led to the discomforts in visual acuity in $46 \%$ respondents.

Conclusion: The survey has depicted several challenges and various physical discomforts being experienced by the dental professionals during this pandemic. Although wearing PPE is associated with difficulties to dentists but it is extremely essential to wear PPEs for self-protection during the ongoing pandemic.

Keywords: Breathing difficulties, Dental professionals, Headache, Personal protective equipment, Physical discomforts, Vision difficulties International Journal of Clinical Pediatric Dentistry (2021): 10.5005/jp-journals-10005-2061
\end{abstract}

\section{INTRODUCTION}

Coronavirus disease 2019 (COVID-19), an infectious disease caused by severe acute respiratory syndrome coronavirus 2 (SARS-CoV-2), has resulted in an ongoing pandemic. The major transmission route of COVID-19 is via respiratory droplets through close contact and aerosol transmission. ${ }^{1}$ People with COVID-19 suffer from a wide range of symptoms like fever with chills, cough, shortness of breath or difficulty breathing, fatigue, muscle or body aches, headache, sore throat, congestion, or runny nose, nausea or vomiting, and diarrhea. The infection may become serious in about $15 \%$ COVID-positive while $5 \%$ may require oxygen and intensive care. $^{2}$

In the dental practice, standard procedures that involve the use of rotary instruments like high speed turbine and ultrasonic scalers, are associated with the generation of large quantities of aerosols and droplets from the saliva and blood of the patient. These can remain suspended in the air for long periods (hours) before settling on the environmental surfaces and can expose the pediatric dentist and other team members to risk of cross infection. The patient's oral fluids, material contamination, and dental unit surfaces can act as sources of contagion both for the dentist and the assistant, and for the patient himself or herself. ${ }^{3}$ Thus, it has become extremely important that personal protective equipment (PPE) be worn by dentists and chair side assistants in the dental settings during all the times such as screening, oral examination and performing required dental

\footnotetext{
${ }^{1-5}$ Department of Pedodontics and Preventive Dentistry, All India Institute of Medical Sciences, New Delhi, India

Corresponding Author: Kalpana Bansal, Department of Pedodontics and Preventive Dentistry, All India Institute of Medical Sciences, New Delhi, India, Phone: +919810105132, e-mail: drkalpanabansal@gmail.com

How to cite this article: Bansal K, Saji S, Mathur VP, et al. A Survey of Self-perceived Physical Discomforts and Health Behaviors Related to Personal Protective Equipment of Indian Dental Professionals during COVID-19 Pandemic. Int J Clin Pediatr Dent 2021;14(6):784-789.

Source of support: Nil

Conflict of interest: None

procedures which range from least aerosol-generating procedures (AGP) such as radiographic examination, atraumatic restorative procedures to high aerosol-generating ones such as endodontics, crown preparations, and oral surgical procedures requiring using rotary instruments. In such clinical scenario, it is mandatory for dental healthcare workers to wear PPE. ${ }^{4}$ A study has found that the majority of frontline healthcare workers developed new-onset headaches due to the wearing of PPE for long hours. The study involved 158 healthcare workers at National University Hospital (NUH) who donned PPE while caring for COVID-19 patients in high-risk hospital areas. ${ }^{5}$ Healthcare workers have also reported profuse sweating, dizziness, difficulty in breathing, rashes, nasal bridge scarring in another recent study. ${ }^{6}$
} org/licenses/by-nc/4.0/), which permits unrestricted use, distribution, and non-commercial reproduction in any medium, provided you give appropriate credit to the original author(s) and the source, provide a link to the Creative Commons license, and indicate if changes were made. The Creative Commons Public Domain Dedication waiver (http://creativecommons.org/publicdomain/zero/1.0/) applies to the data made available in this article, unless otherwise stated. 
Literature search showed that not a single study has been reported so far about how the PPE is affecting the dental professional's well-being in terms of the physical stresses and discomforts while rendering the dental treatment after the onset of the coronavirus pandemic. Hence, this study was planned with the aim to assess the experiences in terms of physical discomforts and related health issues faced by dental professionals while wearing PPE in dental clinical settings during the COVID-19 pandemic.

\section{Materials and Methods}

This was a cross-sectional comprehensive survey conducted by a team of researchers from a tertiary care hospital from November to December 2020 among dental professionals of various regions of the country using online questionnaire tool in English. Permission to conduct the survey was taken from the Institute's Ethics Committee. Snowball sampling method was used. Dentists working on the dental patients during the COVID-19 pandemic wearing PPE were included in the study. The survey was set up in a way that the potential participant must click on a "button" as a response indicating that he/she agrees to participate. Once the 'button' is selected, the potential participant was directed to the research survey questionnaire. That is, the survey questions were not enabled to be viewed by participants until he/she clicks to consent for voluntary participation.

The electronic questionnaire was sent using email and other contemporary social media. Initially, the questionnaire link was sent to 20-30 dental professionals through e-mail and were requested to give their feedback about the comprehensibility of the items. Based on their feedback, minor changes were done in the language and thus the questionnaire was validated. The final questionnaire link was then shared through email and social media methods to potential participant dental professionals of various specialties throughout the country. Participation was completely voluntary. The confidentiality of the data was maintained.

The non-responders were sent reminders at a week's interval for three times. The questionnaire contained five sections. In Section 1 , the information about the purpose of the survey was described; in Section 2, the willingness to participate (consent) was sought; in Section 3 the demographic information about the participants such as age, gender, the state of the country, type of dental set-up, number of daily working hours, specialty, and their educational level was collected. Questions related to the experiences of the dentists, types of PPE worn, their physical discomforts and health issues related to the various procedures in dentistry (aerosol and nonaerosol-generating and surgical procedures) were asked in Section 4 of the questionnaire. It also included some questions about specific problems faced by the dentists who treat children in their practice.

\section{Statistical Analysis}

The spreadsheet from the online survey was downloaded into Microsoft excel sheets and subjected to data analysis using Stata 15.0 (TX, USA) software. Descriptive analysis was done to study the characteristics of the respondents. The associations between various kinds of physical discomforts and various demographic variables such as age, gender, duration of daily working hours and type of dental set up were analyzed using Pearson Chi-square test. The $p$-value less than 0.05 was considered significant.

\section{Results}

Out of 650 dental professionals who were invited to participate, 309 responded to the online questionnaire link. Respondents belonged to almost all the states of the country except from the North-Eastern region. The demographics and the type of dental settings they worked in are given in the Table 1. Maximum respondents were postgraduates (60.8\%) and were from all the dental specialties however, majority (42\%) being pediatric dentists followed by general dentists and endodontists. Maximum respondents were from tertiary care hospitals, government, and educational institutes (39\%) followed by private hospital/single/multiple chair private dental clinic (36\%). Approximately $81 \%$ of respondents worked from 4 to 8 hours a day.

The response of the dentists in terms of the increased PPE's while performing AGP during the pandemic is being presented in Table 2. Though most of the dentists wore faceshield but the pattern of wear varied as shown in the Table 2.

Physical discomforts to PPE's are summarized in Table 3; 64\% respondents had discomfort to $\mathrm{N} 95$ while performing dental procedures and $65 \%$ reported problems on wearing faceshield. Half the dentists felt change or difficulty in vision during diagnostic or treatment procedures due to the faceshield wear. More than three-fourth of dentists reported that they rendered treatment to children and around half of them reported that more verbal communication was required while treating children and it took longer time and more patience to do procedures on children. Half of the respondents reported that the children were scared to see them in the PPEs.

Table 4 presents the discomforts due to PPE in general and specific to $\mathrm{N} 95$ mask and faceshield. Major discomforts reported in general to all PPEs were; excessive sweating, difficulty in breathing and headache followed by thirst, and urinary urgency and hunger. Breathlessness or suffocation was the most common difficulty reported due to N95 (56\%) followed by headache, vision difficulty, skin problem, and ear pain. Less common problems were: difficulty in communication, uncomfortable, chest pain, dry mouth, claustrophobia, allergy, and discomfort in relation to the fit on the nose. Difficulty in vision was observed in $46 \%$ due to fogging or splash on the shield. Headache due to faceshield was reported by $15 \%$ of the respondents. Other discomforts due to faceshield were difficulty in communication and breathing problems, bulk or heaviness on the head, unstable or tightness on head.

A significant association was observed between the presence of headache and difficult breathing and the gender of the dentist ( $p=0.000$ and 0.05 ), respectively as shown in Table 5 . Physical discomforts like thirst and hunger and other discomforts were significantly associated with the age of the dental professional. However, no significant association was found between discomforts such as headache and difficulty in breathing with the age of the dentist $(p<0.05)$.

Association of various physical discomforts specific to N95 and faceshield with age and gender are presented in Table 6. Difficult breathing associated with N95 was more significantly associated with the female dental professionals. No significant association was observed between the physical discomforts specific to N95 and the duration of daily working hours and type of the dental set up. A significant association was found between the gender and the headache associated with the use of faceshield $(p<0.05)$. No significant association was found between the average daily working 
Table 1: Demographic characteristics of the dental professionals $(n=309)$

\begin{tabular}{|c|c|c|}
\hline Variable & Characteristics & Number (\%) \\
\hline Age (in years) & $\begin{array}{l}\cdot 20-30 \\
\cdot 31-40 \\
\cdot>40\end{array}$ & $\begin{array}{l}108(35 \%) \\
87(28.2 \%) \\
114(36.8 \%)\end{array}$ \\
\hline Gender & $\begin{array}{l}\text { - Male } \\
\text { - Female }\end{array}$ & $\begin{array}{l}146(47.2 \%) \\
163(52.8 \%)\end{array}$ \\
\hline Specialty & $\begin{array}{l}\text { - Pediatric and Preventive Dentistry } \\
\text { - General Dentist } \\
\text { - Conservative Dentistry and Endodontics } \\
\text { - Periodontics } \\
\text { - Orthodontics } \\
\text { - Oral and Maxillofacial Surgery } \\
\text { - Prosthodontics } \\
\text { - Public Health Dentistry } \\
\text { - Oral Medicine, Oral Radiology }\end{array}$ & $\begin{array}{l}130(42 \%) \\
65(21.2 \%) \\
39(12.6 \%) \\
19(6.1 \%) \\
17(5.5 \%) \\
15(4.9 \%) \\
15(4.9 \%) \\
7(2.2 \%) \\
2(0.6 \%)\end{array}$ \\
\hline Level of education & $\begin{array}{l}\text { - Undergraduates } \\
\text { - BDS } \\
\text { - Pursuing MDS } \\
\text { - MDS }\end{array}$ & $\begin{array}{l}7(2.3 \%) \\
56(18.1 \%) \\
58(18.8 \%) \\
188(60.8 \%)\end{array}$ \\
\hline $\begin{array}{l}\text { Average daily working hours } \\
\text { in past } 3 \text { months }\end{array}$ & $\begin{array}{l}\cdot<4 \\
\cdot 4-8 \\
\cdot>8\end{array}$ & $\begin{array}{l}40(12.9 \%) \\
249(80.6 \%) \\
20(6.5 \%)\end{array}$ \\
\hline Type of dental set-up & $\begin{array}{l}\text { - Tertiary care hospital/government hospital/educational } \\
\text { institute } \\
\text { - Private hospital/single/multiple chair private dental clinic } \\
\text { - Private Dental College } \\
\text { - Govt Health facility }\end{array}$ & $\begin{array}{l}121(39.2 \%) \\
112(36.2 \%) \\
65(21 \%) \\
11(3.6 \%)\end{array}$ \\
\hline
\end{tabular}

hours and the type of dental set up and the discomforts to the faceshield.

\section{Discussion}

In the very beginning of the declaration of the COVID-19 as the global pandemic, the dental professionals have been recognized as being at the highest risk of infection owing to the transmission of this virus through the respiratory droplets and fomites from the nasal passages of the infected carrier. ${ }^{7}$ COVID-19 had a devastating impact on the dental profession particularly those in the private practice. Dental practices were shut down during the pandemic in several countries which had serious financial implications. ${ }^{8}$ Several dental associations issued the guidelines to limit the dental care to emergencies only. ${ }^{9,10}$

Dental handpieces cause the formation of aerosols and splatter which is commonly contaminated with bacteria, viruses, fungi, and blood. ${ }^{11}$ Oral surgery drills also cause aerosol in addition to splatter. ${ }^{12,13}$ Aerosols are liquid and solid particles $(<50 \mu \mathrm{m}$ diameter) suspended in air for protracted periods. Splatter is a mixture of air, water and/or solid substances (50 $\mu \mathrm{m}$ to several $\mathrm{mm}$ diameter) is of serious concern to the dental team's safety. Dental care personnel face challenges because of their proximity to infected patients as their mouths are open and unmasked during treatment, significantly increasing the potential for direct and indirect exposure to infectious materials.

Though strict protocols have to be followed at screening the dental patients, still in order to render the dental care to the patients, it is mandatory to wear appropriate PPEs to minimize the risk of infections. Several studies have investigated the adverse reactions to PPE in health care personnel and frontline workers but none of the study has reported so far about the discomforts of dental professionals. Through this survey we explored into the self-reported physical discomforts and difficulties the dentists have been facing in the daily clinical practice. On literature search, we found that this is the first of its kind of survey conducted among dental professionals of a country which is hot and humid often. The respondents were from all the states of the country, were in different set up of dental facilities and were using almost all types of PPEs for self-protection from the infection risk. This survey has revealed that most of the dental professionals wearing PPE and treating patients suffering from excessive sweating, headache, difficult breathing, difficult vision, difficult communication, and bulk added to the head region in the form of facial shield. They experienced pain on the nose and behind ear regions in addition to the skin irritations.

The use of $\mathrm{N} 95$ masks has been considered as extremely important for use by all the health care workers to control the spread of aerosols in case of talking, sneezing, or coughing. They are designed to protect users from air particles, including aerosols, with a particle filtration capacity of 0.3 microns of $95 \%$ and have less leakage in the face seal due to the tight fit to the user's face. ${ }^{14}$ However, a large number of respondents (66\%) complained of suffocation, difficult breathing (43\%), headache $(6 \%)$, vision difficulty due to fogging (5\%), pain/marks on the nose and skin irritation (6\%), ear pain (3\%), and exhaustion due to the $\mathrm{N} 95$ wear in the clinical settings. In a previous study by Lim et al., headache associated with mask usage was found in 37.3\% respondents and showed a significant association with the working hours. ${ }^{15}$ However, in our study there was no significant association of working hours and the discomforts experienced. Tight fitting N95 and long hours of working in the patient care 
Table 2: Dentists' experience during the pandemic

\begin{tabular}{|c|c|c|}
\hline $\begin{array}{l}\text { Question- } \\
\text { naire item }\end{array}$ & & Number (\%) \\
\hline $\begin{array}{l}\text { Did you } \\
\text { increase } \\
\text { the number } \\
\text { of items } \\
\text { in your } \\
\text { personal } \\
\text { protective } \\
\text { equipment } \\
\text { (PPE) after } \\
\text { the pan- } \\
\text { demic }\end{array}$ & $\begin{array}{l}\text { Yes } \\
\text { No }\end{array}$ & $\begin{array}{l}294(95.1 \%) \\
15(4.9 \%)\end{array}$ \\
\hline $\begin{array}{l}\text { The PPE you } \\
\text { wear during } \\
\text { aerosol- } \\
\text { generating } \\
\text { procedure } \\
\text { consists of }\end{array}$ & $\begin{array}{l}\text { 1. N95 mask } \\
\text { 2. Surgical mask } \\
\text { 3. Protective goggles } \\
\text { 4. Head cap } \\
\text { 5. Protective gown (water- resistant) } \\
\text { 6. Surgical scrub } \\
\text { 7. Shoe cover } \\
\text { 8. Faceshield } \\
\text { 9. Washable cloth surgical gown } \\
\text { 10. All of the above }\end{array}$ & $\begin{array}{l}246(79.6 \%) \\
188(60.8 \%) \\
184(59.5 \%) \\
252(81.6 \%) \\
217(70.2 \%) \\
132(42.7 \%) \\
155(50.2 \%) \\
258(83.5 \%) \\
104(33.7 \%) \\
88(28.5 \%)\end{array}$ \\
\hline $\begin{array}{l}\text { When do } \\
\text { you wear } \\
\text { faceshield? }\end{array}$ & $\begin{array}{l}\text { 1. All the time while in patient- } \\
\text { treating area. } \\
\text { 2. Only during aerosol-generating } \\
\text { procedures } \\
\text { 3. During both aerosol and non- } \\
\text { aerosol-generating procedures. } \\
\text { 4. During examination, aerosol and } \\
\text { non-aerosol-generating proce- } \\
\text { dures. } \\
\text { 5. I do not wear faceshield }\end{array}$ & $\begin{array}{l}143(46.3 \%) \\
60(19.4 \%) \\
40(12.9 \%) \\
62(20.1 \%) \\
4(1.3 \%)\end{array}$ \\
\hline
\end{tabular}

(more than 6 hours) can lead to skin damage due to sweat and skin compression in healthcare workers (HCW) in Hubei, China. ${ }^{16} \mathrm{Hu}$ $\mathrm{K}$ et al. ${ }^{17}$ showed that the most common adverse skin reactions among HCW using PPE include nasal bridge scarring, facial itching, skin damage, dry skin, rash, chapped skin, and wheals.

Physical discomforts related to faceshield have never been reported in the literature. However, being at a very high risk of transmission in the dental operatory, the wear of faceshield is mandatory particularly when the AGPs are being performed on the patients. In this study $65 \%$ respondents had difficulty in vision, headache, communication problems, uncomfortable breathing, and added bulk on the head with the use of faceshields. Headache was more significantly associated with the gender and the age of the dentist. Thus, vision problems were more owing to the faceshield use perse while some could be attributed to the fogging of the faceshield.

Treating pediatric dental patients has become more challenging as reported by more than half of the respondents that children get scared on seeing dentists in PPEs. More time and verbal communication was required in handling the children since PPE hamper the direct eye to eye contact of the dentist with the child which is very important in handling anxious children.

On analysis of the associations between the PPEs and various physical discomforts, it was observed that certain problems such as headache and difficult breathing were more significantly found in female dental professionals. Similar observations have been reported by Xia W et al. ${ }^{18}$ In another study in Turkey, the discomfort due to PPE usage was reported more by the females ${ }^{19}$ No significant
Table 3: Responses to the questions related to discomforts with the PPE

\begin{tabular}{|c|c|c|}
\hline $\begin{array}{l}\text { Do you experience any } \\
\text { physical discomforts } \\
\text { while wearing PPE? }\end{array}$ & $\begin{array}{l}\text { Yes } \\
\text { No }\end{array}$ & $\begin{array}{l}297(96 \%) \\
12(4 \%)\end{array}$ \\
\hline $\begin{array}{l}\text { Do you feel any dif- } \\
\text { ficulty due to usage of } \\
\text { N95 masks? }\end{array}$ & $\begin{array}{l}\text { Yes } \\
\text { No }\end{array}$ & $\begin{array}{l}198(64 \%) \\
111(36 \%)\end{array}$ \\
\hline $\begin{array}{l}\text { Do you feel any dif- } \\
\text { ficulty due to usage of } \\
\text { faceshield? }\end{array}$ & $\begin{array}{l}\text { Yes } \\
\text { No }\end{array}$ & $\begin{array}{l}203(65 \%) \\
106(35 \%)\end{array}$ \\
\hline $\begin{array}{l}\text { Do you feel any change } \\
\text { or difficulty in vision } \\
\text { during diagnostic or } \\
\text { treatment procedures } \\
\text { due to the faceshield? }\end{array}$ & $\begin{array}{l}\text { Yes } \\
\text { No } \\
\text { Sometimes }\end{array}$ & $\begin{array}{l}153(50 \%) \\
39(12.7 \%) \\
114(37.3 \%)\end{array}$ \\
\hline $\begin{array}{l}\text { Do you face any of the } \\
\text { following during the } \\
\text { treatment of children } \\
\text { while wearing PPE }\end{array}$ & $\begin{array}{l}\text { More time required } \\
\text { More patience required } \\
\text { More verbal communica- } \\
\text { tion required } \\
\text { Child gets scared seeing a } \\
\text { doctor in PPE } \\
\text { None of these }\end{array}$ & $\begin{array}{l}145(52 \%) \\
129(46.4 \%) \\
133(48 \%) \\
138(50 \%) \\
44(15 \%)\end{array}$ \\
\hline $\begin{array}{l}\text { Do you render treat- } \\
\text { ment to children }\end{array}$ & $\begin{array}{l}\text { Yes } \\
\text { No }\end{array}$ & $\begin{array}{l}236(76.4 \%) \\
73(23.6 \%)\end{array}$ \\
\hline $\begin{array}{l}\text { Do you perform surgi- } \\
\text { cal procedures? }\end{array}$ & $\begin{array}{l}\text { Yes } \\
\text { No }\end{array}$ & $\begin{array}{l}183(59.2 \%) \\
126(40.8 \%)\end{array}$ \\
\hline
\end{tabular}

association could be found between the discomforts and the average daily working hours, age of the dentist, and type of dental set up. Our results were similar to the Yuan et al. ${ }^{6}$ where $95 \%$ of healthcare workers experienced discomforts while wearing Level 3 PPE.

Strengths of the survey are that the findings are reflecting the opinions of the large number of dentists from all age groups, multiple dental set-ups and how dentists are coping up with the difficult scenario of pandemic using all means of self-protection but catering to the needs of the patients alleviating them from the pain and the suffering. Few limitations in this survey are that this questionnaire was administered online due to the pandemic, hence the participation was voluntary, there is a possibility of bias in reporting by the respondents.

\section{Conclusion}

Thus if we look at the impact that the PPEs have on dentists physical well-being then it can be conclusively stated that there are several physical discomforts which might affect the efficiency of a dental professional. Several professional hazards have been related to this profession ${ }^{20}$ such as musculo-skeletal disorders, eye strain, noise from the air turbine and high speed suction, infection hazards, ionizing, non-ionizing radiations, now in the current situations COVID-19 pandemic has further aggravated the state of the dental professional from financial as well as physical well-being.

It is recommended to drink lots of water during the breaks, before and after the long procedures to alleviate the problem of headaches associated with the PPEs and after-effect of sweating. The intake of sugary drinks and caffeine should be limited. Snacks in the form of fresh fruits, vegetables, and yogurt can help maintaining the hydration levels. In case of difficult breathing, short breaks can be taken when PPEs can be removed when it is safe to do so. There should be provision of safe places to take off the PPEs in the settings without the risk of exposure to air borne pathogens. 
PPE-related Self-reported Physical Discomforts to Dental Professionals

Table 4: Discomforts reported due to PPE in general, and specific to N95 and faceshield

\begin{tabular}{llllll}
\hline $\begin{array}{l}\text { Physical discomfort to } \\
\text { PPE in general }\end{array}$ & Total & Physical discomfort to N95 & Total & Physical discomfort to faceshield & Total \\
\hline Sweating & $217(70 \%)$ & Sweating & $198(64 \%)$ & Sweating & $203(65 \%)$ \\
Difficulty in breathing & $180(58 \%)$ & Difficulty in breathing & $172(56 \%)$ & Vision difficulty & $141(46 \%)$ \\
Headache & $136(44 \%)$ & Headache & $16(5 \%)$ & Headache & $45(15 \%)$ \\
Thirst & $102(33 \%)$ & Vision difficulty & $17(6 \%)$ & Difficulty in communication & $8(3 \%)$ \\
Urinary urgency & $35(11 \%)$ & Skin problem & $17(6 \%)$ & Breathing difficulty & $9(3 \%)$ \\
Hunger & $22(7 \%)$ & Ear pain & $8(3 \%)$ & Bulky & $9(3 \%)$ \\
Other & $23(7 \%)$ & Other $^{* *}$ & $35(11 \%)$ & Other & $5(1.6 \%)$ \\
\hline
\end{tabular}

$\$$ Difficulty in vision, difficulty in communication, speech and hearing, early fatigue, eye irritation, pain behind the ears, pain on the nose, skin irritation, dryness, rashes, allergies

${ }^{*}$ indicates dry skin, skin irritation, rashes, red marks, redness, acne, facial eruptions, mark on nose, pain in nasal area

** indicates movement restrictions, difficulty in communication, sweating, uncomfortable, chest pain, allergy, claustrophobia

Table 5: Association between physical discomfort due to the PPE with age and gender of the dentist

\begin{tabular}{|c|c|c|c|c|c|c|c|c|}
\hline \multicolumn{9}{|c|}{ Age (years) } \\
\hline Physical discomfort & Total & $20-30$ & $31-40$ & $>40$ & $p$-value & $M F$ & $F$ & $p$-value \\
\hline Headache & $136(44 \%)$ & 57 (53\%). & 36 (41\%). & $43(38 \%)$ & 0.066 & $48(33)$ & $88(54)$ & 0.000 \\
\hline Difficulty in breathing & $180(58 \%)$ & $59(55 \%)$ & $58(67 \%)$ & 63. $(55 \%)$ & 0.171 & $71(49)$ & $109(67)$ & 0.001 \\
\hline Urinary urgency & $35(11 \%)$ & $17(16 \%)$ & $9(10 \%)$ & $9(8 \%)$ & 0.189 & $16(11)$ & $19(12)$ & 0.847 \\
\hline Sweating & $217(70 \%)$ & 85 (79\%). & 57 (66\%). & 75 (34\%) & 0.052 & $102(70)$ & $115(70)$ & 0.895 \\
\hline Thirst & $102(33 \%)$ & 46 (43\%). & 27 (31\%). & $29(25 \%)$ & 0.023 & $48(33)$ & $54(33)$ & 0.962 \\
\hline Hunger & $22(7 \%)$ & $13(12 \%)$ & 6 (7\%). & $3(3 \%)$ & 0.025 & $12(8)$ & $10(6)$ & 0.477 \\
\hline Other $\$$ & $23(7 \%)$ & $1(1 \%)$ & 3 (3\%). & $19(17 \%)$ & 0.000 & $13(9)$ & $10(6)$ & 0.355 \\
\hline
\end{tabular}

$\$$ Difficulty in vision, difficulty in communication, speech and hearing, early fatigue, eye irritation, pain behind the ears, pain on the nose, skin irritation, dryness, rashes, allergies

Table 6: Association between physical discomfort specific to N95 and faceshield and age and gender of the dentist

\begin{tabular}{|c|c|c|c|c|c|c|c|c|}
\hline \multicolumn{9}{|c|}{ Age (years) $N(\%)$} \\
\hline Physical discomfort to N95 & Total & $20-30$ & $31-40$ & $>40$ & $p$-value & $M(\%) F(\%)$ & $F(\%)$ & $p$-value \\
\hline Overall & $198(64 \%)$ & 68 (63\%). & 59 (68\%). & $71(68 \%)$ & 0.688 & $86(59)$ & $112(69)$ & 0.073 \\
\hline Difficulty in breathing & $172(56 \%)$ & $44(41 \%)$ & 47 (54\%). & 46 (40\%). & 0.108 & $55(38)$ & $82(50)$ & 0.026 \\
\hline Headache & $16(5 \%)$ & $2(2 \%)$ & $6(7 \%)$ & $8(7 \%)$ & 0.143 & $5(3)$ & $11(7)$ & 0.188 \\
\hline Vision difficulty & $17(6 \%)$ & $6(6 \%)$ & $5(6 \%)$ & $6(5 \%)$ & 0.988 & $10(7)$ & $7(4)$ & 0.325 \\
\hline Skin problem* & $17(6 \%)$ & $11(10 \%)$ & 4 (5\%). & $2(2 \%)$ & 0.022 & $6(4)$ & $11(7)$ & 0.310 \\
\hline $\begin{array}{l}\text { Ear pain } \\
\text { Yes }\end{array}$ & $8(3 \%)$ & $4(4 \%)$ & $2(2 \%)$ & $2(2 \%)$ & 0.673 & $5(3)$ & $3(2)$ & 0.483 \\
\hline Other** & $35(11 \%)$ & $8(7 \%)$ & $11(13 \%)$ & $16(14 \%)$ & 0.268 & $15(10)$ & $20(12)$ & 0.580 \\
\hline \multicolumn{9}{|c|}{ Physical discomfort to faceshield } \\
\hline Overall & $203(65 \%)$ & $73(68 \%)$ & $55(63 \%)$ & $75(66 \%)$ & 0.815 & $\begin{array}{l}90(62) \\
56(38)\end{array}$ & $\begin{array}{l}113(69) \\
50(31)\end{array}$ & 0.156 \\
\hline Headache & $45(15 \%)$ & $24(22 \%)$ & $12(14 \%)$ & $9(8 \%)$ & 0.010 & $13(9)$ & $32(20)$ & 0.008 \\
\hline
\end{tabular}

* indicates dry skin, skin irritation, rashes, red marks, redness, acne, facial eruptions, mark on nose, pain in nasal area

** indicates movement restrictions, difficulty in communication, sweating, uncomfortable, chest pain, allergy, claustrophobia

More emphasis should be on the preventive and minimal invasive dentistry avoiding the need to use the high speed aerosolgenerating handpieces and ultrasonic scaling systems. However, following the protective protocols in the dental settings is of utmost importance during these challenging times of global pandemic.

\section{ACKNOWLEDgments}

The authors acknowledge the help of Dr M Kalaivani, Scientist at Department of Biostatistics, for assisting in the statistical analysis.

\section{Ethical Approval}

The study was ethically approved by the Institute's Ethics Committee.

\section{References}

1. Han $\mathrm{Y}$, Yang $\mathrm{H}$. The transmission and diagnosis of 2019 novel coronavirus infection disease (COVID-19): a Chinese perspective J Med Virol 2020;92:639-644. DOI: 10.1002/jmv.25749

2. Centers for Disease Control and Prevention. 2020. Coronavirus Disease 2019 (COVID-19) - Symptoms. [online] Available at: https:// 
www.cdc.gov/coronavirus/2019-ncov/symptoms-testing/symptoms. html [Accessed 7 September 2020].

3. Luzzi V, lerardo G; Bossù M, et al.. COVID-19: pediatric oral health during and after the pandemics. Preprints 2020, 2020040002. DOI 10.20944/preprints202004.0002.v1

4. Wang J, Liu F, Tan JBX, et al. Implementation of infection prevention and control in acute care hospitals in Mainland China - a systematic review. Antimicrob Resist Infect Control 2019;8:32. DOI: 10.1186/ s13756-019-0481-y

5. Ong JJY, Bharatendu C, Goh Y, et al. Headaches associated with personal protective equipment - a cross-sectional study among frontline healthcare workers during COVID-19. Headache 2020;60(5):864-877. DOI: 10.1111/head.13811

6. Yuan N, Yang WX, Lu JL, et al. Investigation of adverse reactions in healthcare personnel working in Level 3 barrier protection PPE to treat COVID-19. Postgrad Med J 2021;97(1148):351-354. DOI: 10.1136/ postgradmedj-2020-137854

7. Fallahi HR, Keyhan SO, Zandian D, et al. Being a front-line dentist during the Covid-19 pandemic: a literature review. Maxillofac Plast Reconstr Surg 2020;42(1):12. DOI: 10.1186/s40902-020-00256-5

8. Coulthard P. Dentistry and coronavirus (COVID-19) - moral decision-making. Br Dent J 2020;228(7):503-505. DOI: 10.1038/ s41415-020-1482-1

9. Protocol Covid 19 - Indian Dental Association. Available at www.ida. org.in > pdf > Covid19-IDA Protocol.

10. Centre for Disease Control. Interim Infection Prevention and Control Guidance for Dental Settings During the Coronavirus Disease 2019 (COVID-19) Pandemic. Accessed from https://www.cdc.gov/ coronavirus/2019-ncov/hcp/dental-settings.html

11. Szymańska J. Dental bioaerosol as an occupational hazard in a dentist's workplace. Ann Agric Environ Med 2007;14(2):203-207. PMID No- 18247451
12. Ishihama K, lada S, Koizumi $H$, et al. High incidence of blood exposure due to imperceptible contaminated splatters during oral surgery. J Oral Maxillofacial Surg 2008;66:704-710. DOI: 10.1016/j. joms.2007.06.663

13. Al-Eid RA, Ramalingam S, Sundar C, et al. Detection of visually imperceptible blood contamination in the oral surgical clinic using forensic luminol blood detection agent. J Int Soc Prev Community Dent 2018;8:327-332. DOI: 10.4103/jispcd.JISPCD_10_18

14. Arellano-Cotrina J, Marengo-Coronel N, Atoche-Socola K, et al. Effectiveness and recommendations for the use of dental masks in the prevention of COVID-19: a literature review. Disaster Med Public Health Prep 2020:1-6. DOI: 10.1017/dmp.2020.255

15. Lim EC, Seet RC, Lee KH, et al. Headaches and the N95 face-mask amongst healthcare providers. Acta Neurol Scand 2006;113(3):199-202. DOI: $10.1111 / j .1600-0404.2005 .00560 . x$

16. Lan J, Song Z, Miao X, et al. Skin damage among health care workers managing coronavirus disease-2019. J Am Acad Dermatol 2020;82(5):1215-1216. DOI: 10.1016/j.jaad.2020.03.014

17. Hu K, Fan J, Li X, et al. The adverse skin reactions of health care workers using personal protective equipment for COVID-19. Medicine 2020; 99:24:e20603. DOI: 10.1097/md.0000000000020603

18. Xia W, Fu L, Liao $H$, et al. The physical and psychological effects of personal protective equipment on health care workers in Wuhan, China: A cross-sectional survey study. J Emerg Nurs 2020;46(6):791-801. e7. doi: 10.1016/j.jen.2020.08.004

19. Çiriş Yildiz C, Ulaşli Kaban H, Tanriverdi FŞ. COVID-19 pandemic and personal protective equipment: Evaluation of equipment comfort and user attitude. Arch Environ Occup Health 2020; 16:1-8. DOI: 10.1080/19338244.2020.1828247

20. Ayatollahi J, Ayatollahi F, Ardekani AM, et al. Occupational hazards to dental staff Dent Res J (Isfahan) 2012;9(1):2-7. DOI: 10.4103/17353327.92919 